\title{
Agricultura e produção do espaço urbano: reflexões para uma agenda de pesquisa
}

\section{Agriculture and production of urban space: reflections for a research agenda}

Ricardo Theophilo Folhes - Doutor em Geografia pelo Instituto de Altos Estudos da América Latina, Universidade Paris 3 Sorbonne Nouvelle em cotutela com o programa de Pós-Graduação em Ciências Ambientais (PPGCA) da Universidade Federal do Pará (UFPA). Coordenador do Programa de Pós-Graduação em Desenvolvimento Sustentável do Trópico Úmido (PPGDSTU) do Núcleo de Altos Estudos Amazônicos (NAEA) da Universidade Federal do Pará (UFPA). E-mail: folhes@ufpa.br

Harley Silva - Doutor em Economia pela Universidade Federal de Minas Gerais (UFMG). Professor da Universidade Federal do Pará (UFPA). E-mail: harley74@gmail.com

Raul Ventura Neto - Doutor em Desenvolvimento Econômico pelo Instituto de Economia da Universidade Estadual de Campinas (Unicamp). Professor da Faculdade de Arquitetura e do Programa de Pós-Graduação em Arquitetura e Urbanismo (PPGAU) da Universidade Federal do Pará (UFPA). E-mail: netoventuraraul@gmail.com

Kevin Gabriel Leite da Silva - Graduando em Geografia pela Universidade Federal do Pará (UFPA). E-mail: kevgabr.kg@gmail.com

Ciria Cristiane da Rosa - Mestranda no Programa de Pós-Graduação em Desenvolvimento Sustentável do Trópico Úmido (PPGDSTU), Núcleo de Altos Estudos Amazônicos (NAEA) da Universidade Federal do Pará (UFPA). E-mail: ciriarosa1994@gmail.com

Aelton Dias Costa - Graduando em Geografia pela Universidade Federal do Pará (UFPA). E-mail: aeltondcosta@gmail.com

\section{Resumo}

$\mathrm{O}$ artigo tem o objetivo de apresentar os resultados iniciais de uma revisão bibliográfica sobre Agricultura Urbana (AU), os quais podem vir a apoiar a elaboração de uma agenda de pesquisa nas regiões metropolitanas do Estado do Pará, Amazônia brasileira. Partimos de uma revisão bibliográfica da literatura nacional e internacional sobre o tema, na qual analisamos conceitos, abordagens e desafios. Concluímos ressaltando a necessidade de a AU ser problematizada no âmbito dos fenômenos de produção do espaço urbano-regional, causadores de desigualdades socioeconômicas e espaciais que representam as maiores dificuldades estruturais à agricultura urbana.

\section{Palavras-chave}

Sistemas Alimentares. Produção do Espaço. Socialização da Natureza. Comunidades que Sustentam a Agricultura.

\begin{abstract}
The article aims to show the preliminary results of a bibliographical review on urban agriculture $(\mathrm{AU})$ that may come to support the elaboration of a research agenda in the metropolitan regions of the state of Pará, Brazilian Amazon. We started from a bibliographic review of the international and national literature on the topic, in which we analyzed concepts, approaches and challenges. We conclude by emphasizing the need to problematize $\mathrm{AU}$ in the context of the production phenomena of the urban-regional space. These are the causes of socioeconomic and spatial inequalities that represent the greatest structural challenges for urban agriculture.
\end{abstract}

\section{Keywords}

Food Systems. Production of Space. Sociability of Nature. Community-Supported Agriculture. 


\section{INTRODUÇÃO}

A agricultura ganhou interesse público renovado após as infecções de Covid-19 - registradas inicialmente na China em dezembro de 2019 - terem se espalhado nos meses seguintes por todos os continentes do mundo. A ameaça de que as medidas para contenção da propagação do novo coronavírus (isolamento social e interrupção dos fluxos de mercadorias e pessoas) pudessem causar uma crise alimentar mundial sem precedentes estimulou reflexões e debates sobre as relações entre agricultura, natureza e sociedade. Uma nuance importante dos debates foi a atenção destinada à agricultura praticada nas chamadas áreas urbanas e periurbanas.

A agricultura urbana costuma ganhar relevo em momentos de crises econômicas e humanitárias. Na literatura dedicada ao tema, são citadas as grandes campanhas nacionais em favor da produção urbana de alimentos como forma de amenizar as crises alimentares durante os períodos de guerra e pós-guerra nos EUA e na Europa (DRAKE; LAWSON, 2014; GINN, 2012). A experiência cubana também recebe atenção da literatura especializada. No início da década de 1990, a dissolução da União Soviética pôs fim ao apoio prestado pelo bloco de países comunistas a Cuba, com o objetivo de minimizar os impactos negativos do bloqueio econômico imposto pelos EUA ao país caribenho. Procurando superar a crise, o Estado cubano conduziu uma grande campanha de incentivos à agricultura nas cidades, com o objetivo de melhorar as condições gerais de alimentação no país (PALMA et al., 2015; LOPES; LOPES, 2012).

Mais recentemente, no fim de 2007, uma crise econômica de alcance global provocou a elevação do preço dos alimentos, ocasionando uma das maiores crises alimentares das últimas décadas. Nesse caso, houve a congruência de três fenômenos. De um lado, secas e chuvas intensas prejudicaram as colheitas em países produtores de commodities agrícolas, como milho e soja. De outro, o crescimento econômico de países emergentes demandou mais importações de alimentos para dar conta dos novos padrões de consumo experimentados à época. A essa conjuntura veio somar-se a alta do preço do petróleo, decisiva para o aumento da demanda por biocombustíveis, fato que desencadeou a elevação dos preços de cereais e grãos e o consequente impacto nas cadeias de produção de proteína e no consumo direto nas grandes cidades (FAO, 2008; TEIXEIRA, 2007). Dessa forma, a alta dos preços dos alimentos resultou em uma significativa ampliação do número de pessoas em situação de insegurança alimentar. A fome, em 2009, atingia 1,02 bilhões de pessoas no planeta, o pior índice desde 1970 (FAO, 2009). 
Esse evento foi recuperado durante a pandemia de Covid-19, nas discussões sobre a agricultura urbana. Ora se amparando na problematização das diferenças estruturais entre os sistemas agroalimentares observados na atualidade (NIEDERLE; WESZ JUNIOR, 2018), ora ressaltando a força homogeneizadora dos regimes alimentares dominantes (MCMICHAEL, 2016) ou, como preferem alguns, dos impérios alimentares ocidentais (PLOEG, 2008), muito se debateu em Lives e Webinars, em 2020, sobre a complexa relação entre campo e cidade, produção e consumo, sociedade e natureza, num momento em que os sistemas agroalimentares dominantes são marcados pelo distanciamento entre produtores e consumidores.

Os sistemas agroalimentares controlados mundialmente pelo agronegócio, marcados pelo domínio do capital financeiro, industrial e varejista sobre a produção e a circulação de alimentos por longos circuitos espaciais entre áreas produtoras e consumidoras diferem-se estruturalmente dos sistemas agroalimentares organizados a partir de vínculos de proximidade entre agricultores familiares e consumidores (SCHNEIDER et al., 2020).

A crise pandêmica foi a manifestação mais recente de um processo que remonta aos impactos negativos do crescimento urbano-industrial e do agronegócio sobre a biodiversidade e o equilíbrio ecológico-climático global, decorrentes, dentre outros fatores, da homogeneização produtiva nos campos e nas cidades. Nesse processo, dois movimentos são importantes. O primeiro se refere à expansão e ao adensamento espacial das cidades que continuamente convertem vazios urbanos, áreas naturais e agrícolas em bairros, condomínios, loteamentos, distritos industriais, zonas comerciais etc. O segundo está vinculado à crescente homogeneização dos ambientes naturais pelo agronegócio e sua grande capacidade de incorporar terras destinadas a outros usos. A demanda por relocalização dos sistemas alimentares conferiu à agricultura urbana um lugar importante nos debates, ao mesmo tempo em que estimulou o questionamento de como esses dois movimentos podem restringi-la, ou mesmo inviabilizá-la.

Atento a esses dois movimentos, este artigo tem o objetivo de apresentar os resultados iniciais de uma revisão de literatura nacional e internacional que apoie a elaboração de uma agenda de pesquisa sobre a agricultura urbana, nas regiões metropolitanas paraenses, a ser desenvolvida pelos autores e outros parceiros. Trata-se de uma iniciativa de pesquisadores e alunos da Universidade Federal do Pará (UFPA) e do Instituto Nacional de Ciência e Tecnologia (INCT) Odisseia. No entanto, no presente texto, não revisamos a literatura que aborda as muitas experiências de agricultura urbana já existentes nessas regiões, tema que será desenvolvido em um próximo artigo. 
Após essa introdução, as duas seções seguintes apresentam a revisão da literatura sobre a agricultura urbana. A seção 2 foca a evolução do debate acadêmico sobre conceitos, áreas temáticas, desafios e políticas públicas. A seção 3 faz introdução às motivações e formas de organização de coletivos formados por consumidores e agricultores, que se apresentam como caminhos promissores para a relocalização dos sistemas alimentares em áreas urbanas. A seção 4, com o apoio da revisão, apresenta alguns elementos que entendemos ser centrais para uma agenda de pesquisas sobre Agricultura Urbana (AU) e que serão potenciais eixos temáticos das nossas futuras pesquisas sobre o tema nas regiões metropolitanas do Estado do Pará. A seção 5 é constituída por nossas considerações finais. Ressaltamos que a mudança da relação entre alimentos e cidades tem potencial para revitalizar as áreas urbanas, desde que haja o compromisso de se enfrentar as causas profundas das desigualdades socioespaciais e dos sistemas alimentares, além do desejo de aumentar o controle local sobre o que se produz e se consome.

\section{UMA APROXIMAÇÃO COM A EVOLUÇÃO DO DEBATE ACADÊMICO SOBRE A AGRICULTURA URBANA}

Nesta seção, apresentamos o resultado do primeiro esforço de aproximação e síntese da bibliografia nacional e internacional dedicada ao tema da agricultura urbana e periurbana. Por ser mais genérico, utilizaremos o termo "Agricultura Urbana" (AU) ${ }^{1}$ para nos referirmos à agricultura, à pecuária e ao extrativismo praticados nos dois espaços (urbano e periurbano).

Durante o crescimento urbano observado na década de 1960, muitos acadêmicos mostravam-se interessados em compreender as formas e os padrões das mudanças do uso e da ocupação dos espaços urbanos e periurbanos, bem como seus impactos sobre as paisagens e a perda de terras agrícolas para outros usos (residenciais, industriais etc.) com a expansão das cidades (AUBRY, 2014). A experiência acumulada nesses estudos foi fundamental para que as grandes conferências mundiais sobre os problemas ambientais e ecológicos do planeta, ocorridas a partir da década de 1970, salientassem os impactos do crescimento urbano sobre a sustentabilidade das cidades, influenciando a inserção de temas referidos à ecologia e economia nas pesquisas sobre AU.

\footnotetext{
$\mathrm{Na}$ literatura inglesa, são comuns os termos "urban agriculture"; "urban farms"; "urban gardens"; "bousehold gardens", "school gardens", "community gardens", "allotment gardens", "agricultural parks". "Farms" diferenciam-se de "gardens" pela maior inclinação de produzir visando à comercialização, o que de maneira nenhuma retira dos variados tipos de "gardens" relações mais ou menos constantes com os mercados. "Agricultural parks" referem-se a experiências rurais não raro com agricultores inexperientes moradores das cidades e migrantes. Na literatura francesa, são comuns os termos "agriculture périurbaine", "agriculture intra-urbaine", "agriculture urbaine".
} 
O diagnóstico das motivações de produzir alimentos nas cidades foi diferente entre o norte e o sul global (CORRÊA et al., 2020) e entre regiões ricas e pobres de uma mesma cidade ou região metropolitana. Diante disso, instituições de pesquisa, ONGs e agências de cooperação internacional passaram a canalizar esforços para a criação de uma agenda de debates com os governos nacionais, com vistas a discutir e estimular a AU (MCCLINTOCK, 2010). Um marco dessas iniciativas foi, em 1996, a publicação, pelo Programa das Nações Unidas para o Desenvolvimento (PNUD), do documento Urban Agriculture, Food, Jobs and Sustainable Cities, na Segunda Conferência das Nações Unidas sobre os Assentamentos Humanos (Habitat II), realizada na Turquia.

Tanto em documentos normativos produzidos por organizações da cooperação internacional como no debate acadêmico defendia-se, na década de 1990, que a AU poderia servir como contraponto a fenômenos ambientais indesejados. Nesses termos, assumia-se que a AU poderia contribuir com a "ambientalização das cidades", além de proporcionar a melhoria da qualidade e a diminuição dos custos com a alimentação e, de quebra, ter potencial para gerar renda em diferentes contextos socioespaciais (YEUNG, 1987). Desde então, o aproveitamento de resíduos residenciais e industriais, o combate ao aumento térmico via arborização das cidades e o incremento do efeito de absorção de gases causadores de efeito estufa, graças à atividade fotossintética das plantas cultivadas ou presentes em reservas ambientais, passaram a ser benefícios enfatizados na literatura (ACKERMAN et al., 2014; WILSON, 2008).

A busca por medidas e argumentos ecológicos de apoio à agricultura urbana logo se vincularia às medidas e aos argumentos de orientação econômica. Afinal, o incremento da produção local de alimentos poderia melhorar as condições gerais de alimentação e diminuir a distância entre produtores e consumidores, reduzindo, assim, os custos de transporte. Ao mesmo tempo em que teria potencial para contribuir com a redução global da emissão de combustíveis fósseis provenientes da circulação de veículos automotores empregados nas logísticas de abastecimento, o crescimento da AU impactaria positivamente as condições locais de geração de trabalho e renda a partir do encadeamento entre setores de produção, processamento e comercialização de alimentos (MCCLINTOCK, 2010). Desdobradas em diferentes arranjos de integração econômica, essas experiências passaram a ser sistematizadas em muitos lugares do mundo, desde literaturas dedicadas à análise da economia de mercado movimentada pela AU (KAUFMAN; BAILKEY, 2000) até o registro de sua contribuição às economias urbanas populares no âmbito de sistemas alimentares localizados (COELHO; COELHO; EGERER, 2018). 
O interesse pela multifuncionalidade da AU estimulou a elaboração de estudos e relatórios produzidos em escala mundial após a década de 2000. Os relatórios mostraram que, no sul global, a compra de alimentos responde pelo maior gasto das famílias urbanas de baixa renda. O elevado preço dos alimentos nas cidades foi utilizado como argumento para explicar por que a maioria dos agricultores urbanos provinha de famílias de baixa renda que encontravam na agricultura formas de reduzir seus gastos com alimentação, além de gerar renda adicional, principalmente em momentos de crises de abastecimento (FAO, 2012, 2014).

Em um relatório dedicado à América Latina, a FAO salientava que, em 2014, 54\% da população habitava áreas consideradas urbanas (FAO, 2014). Paralelamente, um estudo de abrangência global, realizado no mesmo ano, concluiu que 266 milhões de famílias moradoras de cidades estavam engajadas na produção agrícola nos países do hemisfério sul (THEBO; DRECHSEL; LAMBIN, 2014).

Associado ao debate ecológico e econômico (embora nem sempre de maneira explícita), um campo temático da AU se constituiu em torno dos vínculos entre os sistemas agroalimentares, as dinâmicas populacionais e a sustentabilidade das cidades (COELHO; COELHO; EGERER, 2018), lançando desafios ao planejamento urbano e regional. Em um estudo de grande circulação mundial, Mougeot (2000) defendeu a tese de que uma atividade agropecuária ou extrativista integrada à cidade onde ela ocorre é decisiva para que possa ser compreendida como uma atividade produtiva condizente com o debate das cidades sustentáveis. Assim, para a agricultura urbana contribuir com a sustentabilidade urbana, seriam decisivos, segundo esse autor, tanto o uso eficiente dos saberes, recursos e insumos locais (solo, água, resíduos residenciais e industriais, trabalho etc.), como a oferta dos produtos nas cidades onde eles são produzidos, por meio do autoconsumo, da inserção nos mercados populares e nas redes de troca e solidariedade. Um dos primeiros e ainda hoje mais completos estudos sobre a agricultura urbana realizada em regiões metropolitas brasileiras (SANTANDREU; LOVO, 2007) corroborou essa tese e ressaltou a importância de se pensar e planejar a agricultura urbana em consonância com a gestão territorial e ambiental das cidades e metrópoles.

De fato, a articulação da agricultura urbana com o planejamento urbano e as políticas de extensão rural, inovação e crédito vem recebendo atenção da literatura (ARRAES; CARVALHO, 2015; FAO, 2014). Daí decorre o debate (e muitas experiências práticas) sobre o potencial de um urbanismo agroecológico que harmonize soluções criativas para que a produção de alimentos acessíveis 
à população seja uma preocupação crescente nas intervenções urbanas, contribuindo, assim, para a construção de sistemas alimentares urbanos sustentáveis (RUAF, 2017).

Ainda no campo do urbanismo, a adoção de paisagens funcionais vem sendo alvo de muitos estudos. $\mathrm{Na}$ condição de estruturas urbanas, tais paisagens têm como concepção básica criar capacidade de redução de efeitos de eventos ambientais extremos, decorrentes das mudanças climáticas, ao mesmo tempo em que geram o aproveitamento produtivo das áreas verdes e criam possibilidades de ganhos de alimentação e renda (MCCLINTOCK, 2010; TORNAGHI, 2017).

A AU aporta benefícios a outros temas não focados nessa revisão, como às dimensões educacional, cultural, cognitiva, de lazer e de saúde pública, que vêm, igualmente, recebendo atenção contínua da literatura nacional e internacional (SALDIVAR-TANAKA; KRASNY, 2004; SANTANDREU; LOVO, 2007; ALLEN et al., 2008; RIBEIRO; BOGUS; WATANABE, 2015).

\subsection{OS DESAFIOS AO CRESCIMENTO DA AGRICULTURA URBANA}

Os desafios ao crescimento ou à manutenção da AU são explorados na literatura analisada nesta seção, a partir de duas abordagens principais. A primeira é mais afeita ao tratamento analítico de problemas cujas soluções seriam o desenvolvimento de infraestruturas, tecnologias e gestão racional das cidades. A outra abordagem, mais crítica e amparada nos debates de economia política das cidades e da urbanização, relativiza o potencial de expansão da $\mathrm{AU}$, se não forem enfrentadas as desigualdades na produção do espaço urbano.

Do ponto de vista da infraestrutura, entraves referidos com frequência são o suprimento de água potável encanada, o saneamento básico e a poluição do ar. Essa é a realidade de grande parte das cidades médias e grandes do sul global, que interfere na produção de alimentos com adequadas condições sanitárias, principalmente nas periferias e áreas periurbanas (SANTANDREU; CASTRO, 2007). A busca de respostas a esses problemas tem acontecido em diferentes realidades localizadas e a partir de diferentes tecnologias e arranjos institucionais. Um exemplo são as iniciativas de captação de água de chuva, que têm mobilizado pesquisas com o objetivo de garantir a produção agrícola em áreas urbanas e oferecido respostas a problemas de déficit hídrico (AMOS et al., 2018).

A adoção ou a busca pelo desenvolvimento de técnicas e tecnologias seguem interesses e trajetórias diversas. Há, de um lado, o engajamento de agricultores, ativistas urbanos e movimentos sociais na busca pelo uso de técnicas agroecológicas nos sistemas de cultivos urbanos e no desenvolvimento de 
modelos integrados e inteligentes de coleta e transformação de resíduos urbanos em adubos. Além disso, como veremos detalhadamente mais adiante nesta seção, esses movimentos procuram por inovações nas relações entre consumidores e produtores, o que vem gerando experiências promissoras em todas as regiões do mundo (RUAF, 2017).

No entanto, principalmente nas áreas intraurbanas, a demanda por espaço, luz e água tem levado à busca por opções técnicas baseadas em insumos químicos para o desenvolvimento de produtos e serviços (ARRAES; CARVALHO, 2015). Cultivos verticais, hidropônicos, estufas adaptadas a coberturas de edifícios comerciais e residenciais, públicos e privados, entre outras estratégias têm mobilizado pesquisas e gerado inovações, permitindo a ampliação da produção em áreas urbanas, inclusive naquelas densamente ocupadas.

A própria densidade demográfica e a de renda, reunidas em áreas urbanas densas, permitem um nível de demanda compatível com a remuneração do uso de novas técnicas produtivas. Em algumas situações, a existência de vizinhanças de alta renda permite ainda a oferta de portfólios de serviços mais diversos. É o caso do desenvolvimento de atividades lúdicas, educacionais e paisagísticas que garantem outros tipos de rentabilidade não ligados diretamente à comercialização dos itens produzidos. A esses aspectos se somam inovações em arranjos entre entes públicos e privados, a fim de facilitar a aquisição privada ou cessão pública de espaços em áreas intraurbanas e periurbanas para a produção de itens alimentares destinados a nichos de mercados de alto valor adicionado (PFEIFFER; SILVA; COLQUHOUN, 2014; TORONTO, 2012; TEITEL-PAYNE; KUHNS; NASR, 2016).

Esse contexto mostra que, embora hortas comunitárias e cultivos em espaços domésticos representem o principal lugar no imaginário social da agricultura urbana, a presença de iniciativas altamente capitalizadas, tecnologicamente avançadas e comercialmente sofisticadas é uma tendência emergente (PÖLLING; MERGENTHALER; LORLEBERG, 2016). Na década de 2000, a AU já mostrava ser um mercado promissor a setores capitalizados não só pela oportunidade de exploração de nichos, mas também devido ao barateamento dos custos com logística, dada a aproximação com mercados consumidores (KAUFMAN; BAILKEY, 2000), o que aumenta a pressão sobre as áreas periféricas das grandes cidades, cada vez mais disputadas pelos interesses imobiliários e do agronegócio, conforme abordado na subseção a seguir. 


\subsection{A AGRICULTURA URBANA FRENTE À PRODUÇÃO DESIGUAL DO ESPAÇO}

Nas últimas duas décadas, a AU passou a ser abordada por estudos críticos que analisam como processos estruturais globais dificultam a permanência de espaços à produção de alimentos nas cidades. Tais estudos refletiram também sobre a integração da $\mathrm{AU}$ às contradições socioeconômicas e lutas sociais das cidades. Afinal, se era verdade que a AU poderia contribuir com a geração de trabalho e renda e possibilitar melhores condições ecológicas e alimentares nas cidades, ela esbarrava em muitos desafios que não eram meramente tecnológicos ou de planificação racional, mas inerentes às desigualdades socioespaciais que caracterizam as cidades. Mais atenção se concentrou no fato de que, assim como a habitação, a mobilidade, o lazer, a cultura e muitas outras atividades laborais urbanas, a agricultura urbana estaria sob crescente pressão de agentes e estruturas que organizam a produção desigual do espaço urbano.

A esse respeito, o artigo de Darly e McClintock (2017), intitulado Introduction to Urban Agriculture in the Neoliberal City: Critical European Perspectives, parece-nos emblemático. Nesse texto, os autores exploram o percurso da literatura norteamericana e europeia dedicada a $\mathrm{AU}$, situando a forma como a ampla maioria dessa literatura, em maior ou menor grau, de maneira mais ou menos consciente, teve aderência temática com a racionalidade neoliberal acerca do funcionamento e da gestão das cidades. Embasados em uma ampla revisão bibliográfica, os autores chamaram atenção para a integração da $\mathrm{AU}$ aos processos de produção capitalista da cidade, reforçando o racismo estrutural e as formas de governança neoliberal criadas em oposição ao modelo de "Estado-de-bem-estar-social" de inspiração keynesiana. Para os autores, a pergunta central seria qual o potencial da AU para desafiar radicalmente os processos de neoliberalização e contribuir com a democratização das cidades e a justiça social, ambiental (DARLY; MCCLINTOCK, 2017) e alimentar (TORNAGHI, 2017).

A especulação imobiliária, a articulação entre interesses privados setoriais e governos, a gentrificação e o avanço da mercantilização do solo urbano passaram a ser descritos como fenômenos que inibem ou interrompem a prática agrícola realizada por setores populares (TORNAGHI, 2017), enquanto setores ligados ao grande capital e às tecnologias de ponta ganham espaços, como uma orientação dirigida aos mercados de nichos. Em adição, a especulação imobiliária e a obtenção de terras pelo agronegócio pressionam a agricultura periurbana, com prejuízos ao abastecimento das cidades. 
Em cidades médias do Sul e Sudeste do Pará, por exemplo, a relação entre agronegócio e especulação imobiliária foi determinante para expandir e fragmentar a malha urbana, ao longo da última década. Trata-se de uma dinâmica que combina arranjos políticos para a expansão do perímetro urbano, ou mesmo para promover tentativas de aprovação de novas regiões metropolitanas, como é o caso de Marabá, onde antigas propriedades rurais passaram a ser reconhecidas oficialmente como situadas em espaços periurbanos. Dessa forma, passam a surgir loteamentos direcionados à restrita classe média local, tanto como espaço de moradia, quanto para uma nova rodada de especulação, mas também empreendimentos de Habitação de Interesse Social que contavam com subsídios do Programa Minha Casa, Minha Vida (CARDOSO; MELO; GOMES, 2016). Especificamente em Canaã dos Carajás, cidade impactada por intensas atividades de extração de minério de ferro da Companhia Vale do Rio Doce e que foi palco de um intenso movimento especulativo e financeirizado de conversão de terra rural em loteamento urbano, há uma nova ordem urbana local que tem levado ao abandono de áreas rurais, onde prevaleciam unidades de produção familiar, e à desvalorização das práticas produtivas do campesinato local (CARDOSO; CANDIDO; MELO, 2018).

Kuhns (2017) mostra que é comum, em muitas cidades do mundo, agricultores familiares localizados nos limites entre espaços intraurbanos e periurbanos marcarem também os limites entre a expansão urbana e rios, áreas florestais e campos naturais que, geralmente, estão inseridos na economia agroextrativista e pecuária. Como comentado pelo autor, a expansão urbana e o encarecimento do valor do solo urbano ameaçam esses sistemas de uso da terra e geram tensões fundiárias que findam por influenciar as estratégias de manejo. A insegurança com relação à posse da terra costuma inibir a busca por sistemas de produção mais sustentáveis, cujos resultados produtivos costumam aparecer em intervalos maiores de tempo.

No Brasil, estudos críticos que têm como referência a obra de Lefebvre (1991) discutem problemas semelhantes em diferentes campos, como economia política, ecologia política, geografia, urbanismo, agroecologia, entre outras áreas e disciplinas. Esses trabalhos aproximam a agricultura urbana e as transformações espaciais das áreas urbanas e regiões metropolitanas brasileiras, abordando experiências de resistência política e territorial, organização social e processos de autogestão e elaboração de políticas públicas (CAMPOS; TRAVASSOS, 2019; MELLO, 2019; ALMEIDA; COSTA, 2014; COUTINHO, 2010).

Como mostramos até aqui, a literatura aborda como o adensamento e a expansão das áreas urbanas e a intensificação da urbanização pressionam as 
atividades agrícolas periurbanas de pequena escala e dirigidas para mercados locais e regionais. Esses fenômenos imprimem mobilidade compulsória também às atividades agrícolas intraurbanas, alterando as superfícies agrícolas que seguidamente cedem lugar a outros usos da terra (DARLY; MCCLINTOCK, 2017), e resultam na fragmentação de paisagens que geram importantes serviços ecossistêmicos (LA ROSA et al., 2014) e na perda de terras e territórios de camponeses, indígenas, quilombolas e povos e comunidades tradicionais nas áreas periurbanas (EMPERAIRE; ELOY, 2008).

É importante dizer que não se tem debatido com frequência, na literatura dirigida à $\mathrm{AU}$, os fenômenos que fazem sucumbir os mercados populares. Mesmo quando não são atingidos por processos de deslocamento espacial direto, estruturas como feiras livres e mercados públicos, que dão suporte ao comércio local e popular da $\mathrm{AU}$, constantemente perecem diante da multiplicação de entes das cadeias longas de comercialização ${ }^{2}$, de shopping centers e das grandes redes varejistas, cujas instalações são normalmente apoiadas e facilitadas pelo poder público. O desaparecimento de mercados populares nas áreas intraurbanas e a perda de terras agrícolas nas áreas periurbanas afetam um dos pilares da AU, a proximidade entre produção e consumo (MARQUES; CONTERATO; SCHNEIDER, 2016).

\subsection{POLÍTICAS PÚBLICAS DE APOIO À AGRICULTURA URBANA}

A literatura internacional vem mostrando como movimentos sociais demandam políticas e programas direcionados à AU (BRAND et al., 2011, 2017; RUAF, 2017; LOVELL, 2010). De fato, a AU tem sido integrada à agenda política de formas variadas. A sua afinidade com aspectos urbanísticos, paisagísticos, econômicos, sociais, educacionais e ecológicos abre aos entes públicos de diferentes escalas e setores uma gama de possibilidades de instrumentos de ação. É possível fomentar as atividades da $\mathrm{AU}$, em termos materiais, financeiros e institucionais, tornando ativos seus diferentes atores ou fortalecendo sua atuação. Um enfoque recorrente integra a AU no bojo de políticas de desenvolvimento de sistemas alimentares localizados, em escala municipal ou metropolitana. Nesses casos, os problemas da segurança alimentar criam o elo fundamental, permitindo articular políticas urbanas de educação e abastecimento, por exemplo, ao fortalecimento da AU (BRAND et al., 2011).

Corrêa et al. (2020) realizaram estudo em que analisam palavras-chave e temas mais frequentes em artigos publicados em periódicos europeus e norte-

2 O conceito é empregado em estudos da economia e sociologia rurais, conforme Ploeg (2008). 
americanos. Os pesquisadores mostram que autores de países de alto Índice de Desenvolvimento Humano (IDH) têm como temas mais frequentes intervenções urbanísticas para paisagismo funcional. Autores de países de IDH médio focam as relações entre educação ambiental e sustentabilidade. Já países com o IDH baixo dão ênfase à alimentação e às políticas públicas para o setor.

No Brasil, desde a década de 1990, debate-se a criação de uma política nacional de agricultura urbana, tanto na escala federal como em estados, regiões metropolitanas e municípios. Uma maior inserção da AU na agenda de governo aconteceu com a criação do Programa Fome Zero, pelo Ministério do Desenvolvimento Social e Combate à Fome (MDS), em 2003, e com a elaboração de políticas voltadas à promoção da segurança alimentar no Brasil. Em 2004, o governo federal brasileiro instituiu o Programa Nacional de Agricultura Urbana e Periurbana e, em 2012, o Plano Nacional de Agroecologia e Produção Orgânica. Ambos os planos fazem referência direta à agricultura urbana, mas esses marcos legais têm ainda efeitos práticos bastante limitados.

Um marco legal mais recente é a Portaria $n^{\circ} 467$, de 7 de fevereiro de 2018 (BRASIL, 2018), que instituiu o Programa Nacional de Agricultura Urbana e Periurbana. O programa se inseria no então Ministério do Desenvolvimento Social, mas vem encontrando muitas barreiras com a mudança ministerial e o enfraquecimento institucional da agricultura familiar, além das dificuldades com a perda de força da participação social nos debates e nas decisões tomadas na arena política, com o advento do governo Bolsonaro.

Apesar das tentativas de incluir alguns segmentos de agricultores urbanos em políticas públicas dirigidas à agricultura familiar, como os Programas de Aquisição de Alimentos (PAA) e o Programa Nacional de Agricultura Familiar (Pronaf), há limitações de várias ordens. Além de as poucas disposições legislativas favoráveis à AU serem muito superficialmente implantadas, outras acirram disputas pela terra e pelos territórios em áreas urbanas, periurbanas e rurais, como as mudanças na regularização fundiária urbana e rural trazidas pela Lei no 13.465/2017 (BRASIL, 2017) e a existência de políticas e regulamentos urbanos proibitivos à agricultura, presentes em zoneamentos e planos diretores.

\section{AGRICULTURA: CIRCUITOS CURTOS, SOLIDARIEDADE ENTRE PRODUTORES E CONSUMIDORES E OUTRAS ECONOMIAS URBANAS}

Para além da busca por políticas públicas, muitas iniciativas baseadas na autogestão e na ajuda mútua entre produtores e consumidores vêm construindo 
experiências inovadoras em pequenas e grandes cidades e se aproximando das práticas e ações políticas de movimentos sociais ligados à agroecologia e às reinvindicações pelo "direito à cidade". Entre muitos exemplos sumariados em Ruaf (2017), vale citar as experiências do Movimento Urbano de Agroecologia (MUDA-SP), um coletivo politicamente ativo nas questões relacionadas à agricultura urbana e agroecologia em São Paulo; a experiência, em Belo Horizonte, da Articulação Metropolitana de Agricultura Urbana (ALMEIDA; MORAIS; PAIXÃO, 2012); a Madrid Agrocomposta, na capital espanhola, que busca criar parcerias entre os produtores e consumidores de alimentos, das áreas rurais e urbanas, e aproximá-los de formuladores de políticas públicas (TORNAGHI; HOEKSTRA, 2017).

Esses movimentos geralmente trabalham para construir condições de estabilidade e permanência das cadeias locais de produção. Partindo da constatação de que o chamado livre mercado conduz amiúde à supressão das cadeias locais de produção e consumo, esses agentes tentam construir condições institucionais para a sua permanência.

Uma desses artifícios é a aproximação de consumidores e produtores em processo de ajuda mútua com as chamadas Comunidades que Sustentam a Agricultura (CSA) ou com as Iniciativas Colaborativas de Compras (PREISS; MARQUES, 2015), modalidades institucionais recentes no Brasil e um pouco mais antigas em outros países. Sua existência se dedica à construção de proximidade, confiança mútua e colaboração entre produtores e consumidores. Esses vínculos procuram assegurar estabilidade na relação entre ambos, reduzindo incertezas e riscos e garantindo que os dois grupos se acerquem de seus objetivos básicos: o acesso à alimentação segura e saudável, de um lado, e à geração de trabalho e renda, do outro.

O modelo de relacionamento pode assumir formatos diferentes. Uma das opções é a que estabelece pagamentos antecipados pelos compradores, garantindo a demanda aos alimentos produzidos. $\mathrm{O}$ valor arrecadado com as compras pode também assegurar uma fonte de financiamento da produção. $\mathrm{Na}$ ausência desse pagamento antecipado, pode-se também assegurar pedidos antecipados, de modo que os produtores tenham uma boa estimativa de vendas, próxima ao montante de vendas efetivas. Isso ajusta os esforços e reduz as perdas, além de funcionar como uma sinalização para o ajuste da produção em períodos futuros.

Em todas essas - poucas e não exaustivas - situações de exemplo, as pessoas envolvidas tornam-se coprodutoras. Como comunidade, realizam em conjunto o desenho da produção em sentido estrito, mas também produzem de modo intencional e organizado as relações de um mercado de cadeias curtas, 
funcionando sob controle social. Nesse tipo de cadeia, pequenos e médios produtores enviam semanalmente cestas com produtos a um depósito para a retirada no local ou diretamente à casa dos coprodutores. Além disso, há a realização de diversas reuniões visando discutir os rumos que a produção tomará (ORTEGA et al., 2018).

O embrião das CSA apareceu em 1971, no Japão, sob o nome de Teikei, que, em português, significa "solidariedade". As primeiras Teikei foram organizadas por um grupo de mulheres que buscava emancipação e autonomia nas cadeias de produção de que suas famílias participavam (TORRES, 2018). Entretanto, segundo a literatura, as pioneiras Teikei japonesas ainda não são consideradas CSA, pois faltava somar a elas o fator associativo.

A chamada "economia associativa" foi concebida a partir obra do croata-austríaco Rudolf Steiner (1861-1925). Steiner se opunha à visão liberal de mercados autorregulados e à ideia de economias planificadas centralmente pelo Estado. Em contraposição, propôs uma organização econômica baseada em associações formadas por produtores, consumidores e vendedores que, por meio do diálogo, decidiriam, em todos os sentidos, o rumo do espaço econômico no qual estão inseridos. Posteriormente nasceu o termo "Economia associativa", que se conecta diretamente com as proposições de Steiner e serve para o surgimento das CSA (FERREIRA NETO; TORUNSKY, 2014).

No Brasil, as CSA aparecem pela primeira vez na década de 1990, em Fortaleza/CE, com o objetivo de resolver um problema de escoamento agrícola. Outra experiência importante, também dedicada à resolução do problema do escoamento, aconteceu em 2011, com a fundação da CSA Demétria, em Botucatu-SP. Nesse mesmo ano, teve início a CSA APANFÉ, em Maria da FéMG, e o conceito de CSA foi debatido no Fórum Mundial Social realizado em 2001, em Porto Alegre-RS (TORRES, 2018).

Uma relação importante que se pode fazer é entre as CSA e a concepção de economia compreendida com base no conceito de formas de integração econômica (FIE) por Polanyi (2000). Segundo o autor, para compreender a vida econômica, em sua multiplicidade histórica e social, é insuficiente partir da identificação entre economias e mercado. O mercado é uma das formas de integração por meio da qual as sociedades humanas mantiveram a estabilidade e a unidade de sua reprodução social, tanto historicamente como no mundo contemporâneo. Além dele, as sociedades recorreram, tanto em casos de grupos reduzidos quanto em sociedades amplas e complexas, a pelo menos outras três formas institucionais consolidadas: a domesticidade, a reciprocidade e a redistribuição. 
É possível perceber a presença de características que correspondem a duas das FIE identificadas pelo autor. De um lado, temos a reciprocidade observada entre os agentes que compõem as CSA, pois o processo por meio do qual as CSA funcionam é caracterizado por uma troca recíproca entre produtores, consumidores e comerciantes, em que os elementos envolvidos buscam, por meio dessas trocas e associações econômicas, a garantia de alimentação para si e para os membros de sua família e optam por manter sempre uma relação simétrica baseada no diálogo e na cooperação.

A redistribuição também é uma FIE econômica que pode ser observada nas CSA. Há uma centralidade na forma como os produtos provenientes das associações são obtidos: um grupo repassa um valor aos produtores, esses cuidam de produzir cestas que posteriormente são armazenadas em um ponto específico e distribuídas para todos aqueles que, de alguma forma, contribuíram para a sua produção, dispensando, assim, qualquer necessidade de troca econômica mais individualista e arquitetando uma divisão de trabalho mais igualitária.

Uma importante característica das CSA é a capacidade de garantir a soberania e segurança alimentar das sociedades que participam dela. É direito salvaguardado de todos os povos o acesso a alimentos de qualidade, saudáveis e culturalmente apropriados, e as CSA contribuem diretamente para isso, pois suas práticas culturais vão de encontro ao que foi determinado pela Revolução Verde, já que essas comunidades cultivam sem o uso de agrotóxicos e de outros insumos que contribuem para uma insegurança alimentar.

Além disso, as CSA representam uma alternativa ou uma forma de resistência ao avanço do consumo de produtos do agronegócio e da agricultura industrializada. Diante disso, essas instituições criam opções frente à hegemonia do mercado convencional de produtos alimentares, colocando a possibilidade de organização local e controle social da qualidade alimentar. Esses controles são criados com o concurso da redução da distância física e social entre o consumo e a produção, usando o encurtamento das cadeias de distribuição (ECKERT, 2016). Dessa forma, as CSA atuam como fator de garantia para a segurança alimentar, ao mesmo tempo em que a insegurança alimentar é reforçada pela perda de espaço da agricultura familiar local, como tem ocorrido com frequência nas últimas décadas (MEIRELLES, 2004).

É importante notar que as CSA não são uma prática no meio rural. $\mathrm{Na}$ realidade, ocorrem como uma manifestação da ligação entre os meios rural e urbano. Isso se ilustra no caso citado sobre a formação da primeira CSA no Brasil, em Fortaleza, e em outros casos. Em Belém do Pará, existe a experiência do Grupo para Consumo Agroecológico (GRUCA), um grupo de consumo 
responsável pela articulação entre produtores camponeses e agricultores familiares da Região Metropolitana e consumidores da mesma região. O GRUCA liga-se também a uma movimentação política em torno de grupos que militam nessa causa e trabalham com a difusão e manutenção da culinária e gastronomia da região do estuário amazônico, no quadro do consumo responsável e da alimentação saudável (GONZAGA; GUERRA; ROCHA, 2016).

Os serviços de encomendas e entregas evidenciam o caráter sofisticado e eficiente do serviço, em termos de redução de incertezas e atritos, e a formação de bases de informação para tomada de decisões de produtores e consumidores. Eles põem em evidência também a interação estreita entre os contextos das áreas de produção primaria (rural) e de circulação/consumo (urbano), tirando quase toda dúvida acerca da importância de uma visão espacial e institucional integrada, que é típica das CSA. Por fim, o exemplo mostra também a interação em ato das chamadas formas de integração econômica (POLANYI, 2000), na medida em que atitudes de reciprocidade e redistribuição atuam em conjunção com a realização de trocas, as quais surgem não necessariamente da busca atomizada de interesses, nem a partir dela funcionam, mas de decisões políticas e institucionais de grupos conectados por dimensões de decisão variada.

No meio urbano, as CSA podem apresentar outras qualidades que são pouco valorizadas no meio rural. Entendidas como uma forma institucional ajustada à agricultura urbana, as CSA têm ou podem ter grande importância ambiental para as cidades, visto que podem contribuir para a ocupação de terrenos baldios em áreas mais periféricas, além de auxiliar a capacidade de absorção de água dos solos, característica natural que cada vez mais é impossibilitada pelo avanço do concreto e do asfalto nos meios urbanos; além disso, é uma forma interessante de diminuir as altas temperaturas características da cidade. Dessa forma, pode-se dizer que, além dos fatores sociais e econômicos supracitados, há um fator ambiental que participa da criação das CSA, o que só faz aumentar a importância dessa prática no Brasil rural e urbano.

\section{ALGUNS ELEMENTOS PARA UMA AGENDA DE PESQUISA SOBRE AGRICULTURA URBANA NA AMAZÔNIA}

Almeida e Costa (2014) chamam atenção para o fato de que tanto os conceitos como as abordagens de pesquisas em agricultura urbana estão relacionados a distintas visões de mundo e utopias de sociedade e de cidade. Para entendê-las, os autores salientam que devem ser valorizados o conhecimento 
das diferentes realidades urbanas, do desenvolvimento, a adoção e difusão de tecnologias e os distintos sujeitos envolvidos.

Concordamos com essa perspectiva, mas adicionamos três elementos. Em primeiro lugar, como Darly e McClintock (2017) mostram, as experiências de AU espalhadas pelo mundo estão associadas às especificidades das formações econômico-sociais e espaciais locais. Ou seja, as histórias local, regional e nacional importam, ao mesmo tempo em que as experiências de AU podem ser influenciadas por movimentos políticos, econômicos e culturais globais. Dessa forma, podem estar tanto articuladas a projetos neoliberais e serem dirigidas à reprodução de desigualdades socioeconômicas, como oferecer resistência a esses processos (EIZENBERG; FENSTER, 2015) a partir de iniciativas de autogestão, ajuda mútua e da ação compartilhada de governos e cidadãos em busca do estabelecimento de prioridades municipais coletivas. Como sumariza Coutinho (2010, p. 6): “[a AU] pode assumir a forma de um projeto contra-hegemônico favorável à cooperação e às transformações sociais profundas ou favoráveis ao ideário neoliberal com respostas pontuais às carências urbanas desconsiderando problemas estruturais".

Em segundo lugar, dados os constrangimentos que acometem a produção de alimentos tanto nas cidades como no campo, a abordagem de sistemas alimentares, por focar as intermediações entre produção e consumo, mostra-se capaz de permitir reflexões sobre as relações urbano-rurais.

Apesar de a agricultura urbana ocorrer em lugares com diferentes graus de urbanização, há, no adjetivo urbano, uma noção de fundo que não deve ser perdida de vista e que ajuda a pensá-la teórica e praticamente. Isso nos habilita sugerir um terceiro elemento importante para os estudos de AU, conforme comentado a seguir. Sem se ater diretamente à $\mathrm{AU}$, mas com discussões que ajudam a pensá-la, Silva (2017) discute alternativas ao protagonismo da indústria nas economias urbanas amazônicas. O autor procura expor o conflito entre a exclusividade da organização industrial do espaço e das práticas urbanas e as possibilidades de diversificação colocadas pelas muitas formas possíveis de urbanidade e assentamentos humanos densos. Nesse contexto, o autor discute a valorização da experiência cotidiana e o potencial criador de oportunidades, aprendizado e riqueza das economias urbanas, em especial nos seus circuitos populares. Procura também mostrar de que modo estruturas e práticas urbanas dão suporte ao encontro, à criatividade e à prática política, que, potencializados nesses lugares, podem estimular planos e ações dirigidos às possibilidades de sociabilização da natureza dentro e fora das cidades, mas pensadas a partir delas.

Nesse mesmo sentido, Mello (2019) chama atenção para a forma como a obra de Henri Lefebvre (LEFEBVRE, 1991,2008) oferece abordagens alternativas 
para a apreensão dos fenômenos urbanos, dentre eles, a utopia experimental. Segundo a autora, "a utopia experimental seria essa sociedade factível - como campo de possibilidades urbanas" e, nesse sentido, indaga: "Os movimentos de ocupação de vazios urbanos que se consolidam através de práticas de AU, e ainda, os espaços tradicionais de resistência da AU nas periferias das cidades seriam utopias experimentais?” (MELLO, 2019, p. 12).

Por último, entendemos que, de modo ampliado, as CSA podem ser vistas como uma arquitetura institucional flexível e aberta o bastante para dar suporte à atuação de agentes locais de diversas naturezas que tenham ligações com a AU. Em sua atuação já consolidada, as CSA criam suporte para a resolução de problemas de ajuste entre oferta e demanda, redução de instabilidades e riscos e construção coletiva de segurança alimentar, trabalho, renda.

Porém, consideradas as outras múltiplas dimensões da AU mencionadas neste trabalho - estruturação da ocupação do solo urbano, redução de desigualdades, atuação pró-climática e ambiental etc. -, não resta dúvida de que há potencialidades de multiplicação das frentes possíveis de atuação. Nesses termos, a atuação convergente, na esfera local de pessoas, famílias e coletivos de produtores, consumidores, proprietários de espaços de cultivo, trabalhadores da distribuição, desenvolvedores de técnicas e tecnologias de produção, entre outros agentes, pode fazer frente a desafios mais elevados.

Esses desafios dizem respeito, por certo, a uma atuação organizada, capaz assumir o protagonismo em momentos de atualização no plano diretor dos municípios e nas diretrizes de ordenamento territorial municipal para regiões periurbanas. É preciso avançar na atualização dos instrumentos urbanísticos previstos no Estatuto da Cidade - Lei no 10.257/01 (BRASIL, 2001), ou, até mesmo, na criação de novos instrumentos que permitam lidar com especificidades regionais e problemas cotidianos que podem inviabilizar, por exemplo, práticas de AU nos espaços periurbanos de áreas metropolitanas.

A participação em espaços decisórios de planejamento municipal é fundamental para barrar ondas frenéticas de especulação imobiliária, como as que produziram dezenas de loteamentos nas cidades do Sul e Sudeste do Pará, desarticulando redes de produtores e comunidades extrativistas. O controle político do território passa pela definição de quais usos são desejáveis e possíveis para as áreas periurbanas dos municípios ou da metrópole, para com isso fazer frente aos interesses de grandes agentes econômicos, segmentos do Estado etc., que se interpõem como obstáculo aos benefícios que poderiam decorrer da ampliação da prática da agricultura urbana. 


\section{CONSIDERAÇÕES FINAIS}

Mesmo fora de contextos de crises excepcionais, comentados na introdução deste texto, sabe-se que agricultura, extrativismo e pecuária, em suas diferentes formas, fazem parte do cotidiano das aglomerações urbanas, das pequenas vilas às grandes metrópoles. Espécies vegetais (comestíveis, aromáticas, ornamentais e medicinais) e criações de animais são casualmente encontradas nas áreas intraurbanas e periurbanas, não apenas a partir de experiências coletivas em hortas comunitárias, organizações assistenciais e áreas institucionais (p. ex. servidões de rodovias e de redes elétricas) ou em terrenos baldios, mas também a partir de iniciativas particulares, familiares e coletivas em empresas, residências, sítios, chácaras, fazendas, áreas de uso comum ou ainda como componentes de projetos paisagísticos públicos, realizados em canteiros de avenidas, praças e jardins, os quais cumprem importante papel lúdico, pedagógico, alimentar, produtivo e de geração de renda.

Como vimos, agricultura urbana, intraurbana e periurbana são, entre outros termos, palavras utilizadas em português para designar a agricultura praticada no interior e nas periferias das cidades e regiões metropolitanas. As diferentes formas e funcionalidades socioeconômicas, tecno-produtivas e lúdicas da agricultura praticada em cada um desses espaços influenciam a busca de conceitos muitas vezes reduzidos à dimensão espacial da prática agrícola (PFEIFFER; SILVA; COLQUHOUN, 2014).

Compreendemos que a característica precípua da $\mathrm{AU}$, que de fato a qualifica como urbana, reside na condição de que a produção seja consumida, processada e/ou comercializada nas próprias cidades onde ocorre. Ou seja, mais do que a localização espacial precisa (urbana, intraurbana ou periurbana), corroboramos a definição de que a qualidade urbana da agricultura são seus laços funcionais com as cidades nas quais é praticada (AUBRY, 2014; MOUGEOT, 2000).

Isso significa dizer que o entendimento das relações funcionais e estruturais concernentes aos circuitos de produção e consumo é levado em conta, impedindo que seja qualificada como agricultura urbana a produção de commodities (soja, milho, gado, entre outras) nos espaços periurbanos, ou mesmo nas áreas intraurbanas, quando os sistemas de produção miram mercados globais distantes das áreas de produção.

Esse entendimento salienta a multifuncionalidade da agricultura urbana (alimentar as cidades, construir paisagens naturais, gerar emprego e renda, promover controle térmico, contribuir com a saúde pública, desenvolver atividades terapêuticas e educacionais etc.) em sua diversidade de formas (em 
terrenos ao ar livre com diferentes níveis de tecnologia, em áreas produtivas ou estufas modeladas em terraços e telhados de edifícios, em galpões, em sistemas hidropônicos etc.), estruturas (patronais, familiares, educacionais/assistenciais) e de atores (agricultores, comerciantes e consumidores). Além disso, tal entendimento releva os múltiplos desafios lançados à política e à ciência, dada a necessidade de soluções e inovações que demandam o engajamento inter e transdisciplinar de cientistas (agrônomos, economistas, urbanistas, geógrafos, sociólogos, antropólogos etc.), agricultores, consumidores, movimentos sociais e classe política.

Apesar dos benefícios potenciais que a AU pode gerar, uma análise mais detida sobre o tema permite compreender suas contradições. Em primeiro lugar, como muitos trabalhos mostram, são inúmeros os potenciais impactos positivos em termos cognitivos, educacionais, ecológicos, econômicos e urbanísticos da agricultura urbana, o que justifica o interesse público e o debate acadêmico. Em segundo lugar, diante das suas variadas formas e funções, há o perigo de se essencializar essa atividade como uma panaceia para muitos males urbanos, sem que os problemas estruturais desses problemas, as diferentes racionalidades que orientam a busca de soluções a eles e as contradições que os envolvem sejam devidamente analisados.

São muitos os fatores que limitam ou tensionam a agricultura urbana. Há limitações de acesso a tecnologias, recursos, insumos e serviços e o receio de que a agricultura urbana se vincule a mercados de nichos para as elites urbanas, deixando de ser um potencial instrumento de segurança e soberania alimentar e de garantia do direito à cidade e de acesso às políticas de planejamento urbano-regional. Uma das maiores dificuldades reside nas dinâmicas fundiárias impulsionadas pelas formas de produção do espaço urbano que tensionam o acesso e a manutenção da propriedade ou a posse do solo e sua destinação aos usos residenciais e agrícolas com acesso estável a equipamentos e serviços públicos.

A mudança da relação entre alimentos e cidades, entre produtores e consumidores de alimentos, tem potencial para ampliar a vitalidade, solucionar problemas e criar oportunidades em áreas urbanas. Isso pode ser alcançado, desde que haja também o compromisso de se enfrentar as causas profundas das desigualdades socioespaciais e dos sistemas alimentares, além do desejo de aumentar o controle local sobre o que se produz e se consome. 


\section{AGRADECIMENTOS}

Agradecemos aos pareceristas pelas valiosas críticas e sugestões. Ao CNPQ e aos programas PIBIC e PET/Geografia da Universidade Federal do Pará (UFPA), agradecemos a concessão de bolsas aos alunos de graduação e pós-graduação envolvidos na pesquisa. Ao INCT Odisseia e aos grupos de pesquisa DADESA, URBANA e GPSA Amazônia da UFPA, agradecemos o apoio e frutífero ambiente intelectual. Erros e omissões são de responsabilidade exclusiva dos autores.

\section{REFERÊNCIAS}

ACKERMAN, K. et al. Sustainable food systems for future cities: The potential of urban agriculture. The Economic and Social Review, Dublin, v. 45, n. 2, p. 189-206, 2014.

ALLEN, J. et al. Growing vegetables and values: benefits of NeighborhoodBased Community Gardens for youth development and nutrition. Journal of Hunger \& Environmental Nutrition, [s. l.], v. 3, n. 4, p. 418-439, 2008.

ALMEIDA, D. A. O.; COSTA, H. S. M. Agricultura urbana: uma aproximação possível entre a questão ambiental e a questão urbana. In: SEMINÁRIO NACIONAL SOBRE O TRATAMENTO DE ÁREAS DE PRESERVAÇÃO PERMANENTE EM MEIO URBANO E RESTRIÇÕES AMBIENTAIS AO PARCELAMENTO DO SOLO QUE SERÁ REALIZADO EM BELÉM, 3. 2014, Belém. Anais [...]. Belém: UFPA, 2018. p. 1-18.

ALMEIDA, D. A. O.; MORAIS, L. M. O.; PAIXÃO, L. A. F. Articulação Metropolitana de Agricultura Urbana: espaços e saberes da Agroecologia em Belo Horizonte. Agriculturas, Rio de Janeiro, v. 9, n. 2, p. 23-28, 2012.

AMOS, C. C. et al. A scoping review of roof harvested rainwater usage in urban agriculture: Australia and Kenya in focus. Journal of Cleaner Production, [s. l.], n. 202, p. 174-190, 2018.

ARRAES, N. A. M.; CARVALHO, Y. M. C. Agricultura urbana e Agricultura familiar: interfaces conceituais e práticas. Revista Informações Econômicas, São Paulo, v. 45, n. 6, p. 1-116, nov./dez. 2015.

AUBRY, C. Les agricultures urbaines et les questionnements de la recherché. Pour, Paris, v. 4. n. 224, p. 35-49, 2014. Disponível em: https:// www.cairn.info/revue-pour-2014-4-page-35.htm. Acesso em: 20 fev. 2019 
BRAND, C. et al. L'alimentation des sociétés urbaines: une cure de jouvence pour l'agriculture des territoires métropolitains? VertigO [online], v. 11, n. 2, 2011. Disponível em: http://vertigo.revues.org/11199. Acesso em: 20 fev. 2021.

BRAND, C. et al. Construire des politiques alimentaires urbaines: concepts et démarches. Versalhes: Quae, 2017.

BRASIL. Lei $\mathbf{n}^{\mathbf{0}} \mathbf{1 0 . 2 5 7}$, de 10 de julho de 2001. Regulamenta os arts. 182 e 183 da Constituição Federal, estabelece diretrizes gerais da política urbana e dá outras providências. Brasília, DF: Presidência da República, [2001]. Disponível em: http://www.planalto.gov.br/ccivil_03/leis/leis_2001/110257.htm. Acesso em: 2 mar. 2021.

BRASIL. Lei $\mathbf{n}^{\mathbf{0}} \mathbf{1 3 . 4 6 5}$, de 11 de julho de 2017. Dispõe sobre a regularização fundiária rural e urbana, sobre a liquidação de créditos concedidos aos assentados da reforma agrária e sobre a regularização fundiária no âmbito da Amazônia Legal; institui mecanismos para aprimorar a eficiência dos procedimentos de alienação de imóveis da União; altera as Leis $n^{\text {os }} 8.629$, de 25 de fevereiro de 1993, 13.001, de 20 de junho de 2014 [...] e dá outras providências. Brasília, DF: Presidência da República, [2017]. Disponível em: http:/ /www.planalto.gov.br/ ccivil_03/_ato2015-2018/2017/lei/113465.htm. Acesso em: 2 mar. 2021.

BRASIL. Portaria no 467, de 7 de fevereiro de 2018. Institui o Programa Nacional de Agricultura Urbana e Periurbana. Diário Oficial da União: seção 1, Brasília, DF, n. 29, p. 64, 9 fev. 2018.

CAMPOS, F. S.; TRAVASSOS, L. R. F. C. Agricultura Urbana: entre sociedade e a natureza. In: ENCONTRO NACIONAL DA ASSOCIAÇÃO NACIONAL DE PÓS-GRADUAÇÃO E PESQUISA EM PLANEJAMENTO URBANO E REGIONAL, 18., 2019, Natal. Anais [...]. Natal: UFRN, 2019. p. 1-15.

CARDOSO, A. C. C.; CANDIDO, L. S.; MELO, A. C. C. Canaã dos Carajás: um laboratório sobre as circunstâncias da urbanização, na periferia global e no alvorecer do século XXI. Rev. Bras. Estud. Urbanos Reg. [online], v. 20, n. 1 p. 121-140, 2018.

CARDOSO, A. C. D.; MELO, A. C. C.; GOMES, T. V. O urbano contemporâneo na fronteira de expansão do capital: padrões de transformações espaciais em seis cidades do Pará, Brasil. Revista de Morfologia Urbana, Porto, v. 4, n. 1, p. 5-28, 2016.

COELHO, F. C.; COELHO, E. M.; EGERER, E. M. Local food: benefits and failings due to modern agriculture. Sci. agric., Piracicaba, v. 75, n. 1, p. 84-94, jan. 2018. 
CORRÊA, C. J. P. et al. Semeando a cidade: histórico e atualidades da agricultura urbana. Ambiente \& Sociedade, São Paulo, v. 23, p. 1-22, 2020.

COUTINHO, M. N. Agricultura urbana: práticas populares e sua inserção em políticas públicas. 2010. 205 f. Dissertação (Mestrado em Geografia) Programa de Pós-Graduação em Geografia, Universidade Federal de Minas Gerais, Belo Horizonte, 2010.

DARLY, S.; MCCLINTOCK, N. Introduction to Urban agriculture in the neoliberal city: critical European perspectives. ACME: International Journal for Critical Geographies, [s. l.], v. 16, n. 2, p. 224-231, 2017.

DRAKE, L.; LAWSON, L. J. Validating verdancy or vacancy? The relationship of community gardens and vacant lands in the US. Cities, [s. l.], v. 40, p. 133-142, 2014.

ECKERT, D. A mercantilização em contramovimento: relações de reciprocidade e coesão social na agricultura sustentada pela comunidade em Minas Gerais. 2016. 236 f. Dissertação (Mestrado em Administração) - Escola de Administração, Universidade Federal do Rio Grande do Sul, Porto Alegre, 2016.

EIZENBERG, E.; FENSTER. T. Reframing urban controlled spaces: community gardens in Jerusalem and Tel Aviv-Jaffa. ACME: An International E-Journal for Critical Geographies, [s. l.], v. 14, n. 4, p. 1132-1160, 2015.

EMPERAIRE, L.; ELOY, L. A cidade, um foco de diversidade agrícola no Rio Negro (Amazonas, Brasil). Boletim do Museu Paraense Emílio Goeldi, Belém, v. 3, n. 2, p. 195-211, 2008.

FAO. Food insecurity in the world. Relatório. Roma: FAO, 2008.

FAO. The State of Food Insecurity in the World: Economic crises, impacts and lessons learned. Roma: FAO, 2009.

FAO. Growing greener cities in Africa. First status report on urban and periurban horticulture in Africa. Roma: FAO, 2012.

FAO. Ciudades más verdes em América Latina y el Caribe: um informe de la FAO sobre la agricultura urbana y periurbana en la región. Roma: FAO, 2014. FERREIRA NETO, D. N.; TORUNSKY, F. Agricultura apoiada pela comunidade e a "economia viva" de Rudolf Steiner. Revista Espaço de Diálogo e Desconexão, Araraquara, v. 8, n. 1 e 2, p. 1-10, 2014. 
GINN, F. Dig for Victory! New histories of wartime gardening in Britain. Journal of Historical Geography, [s. l.], v. 38, p. 294-305, 2012.

GONZAGA, N. B.; GUERRA, G. A. D.; ROCHA, A. C. O. GRUCA (Grupo para Consumo Agroecológico): autogestão e cooperação entre consumidores e produtores da Feira Orgânica de Belém e do Assentamento Mártires de Abril (Mosqueiro - Belém - Pará). Cadernos de Agroecologia, [s. l.], v. 10, n. 3, maio 2016. Disponível em: http:/ / revistas.aba-agroecologia.org.br/index.php/ cad/article/view/17381. Acesso em: 2 mar. 2021.

KAUFMAN, J.; BAILKEY, M. Farming inside cities: entrepreneurial urban agriculture in the United States. Cambridge, MA: Lincoln Institute of Land Policy Opitz, 2000.

KUHNS, J. Urban Green Train Modules and Resources (IO2). Module 1: Introduction into urban. Urban Green Train. 2017.

LA ROSA D.; BARBAROSSA, L.; PRIVITERA, R.; MARTINICO, F. Agriculture and the city: a method for sustainable planning of new forms of agriculture in urban contexts. Land Use Pol, [s. l.], n. 41, p. 290-303, 2014. Disponível em: https://doi.org/10.1016/j.landusepol.2014.06.014. Acesso em: 2 mar 2021.

LEFEBVRE, H. The production of space. Oxford; Cambridge: Blackwell, 1991.

LEFEBVRE, H. O direito à cidade. São Paulo: Centauro, 2008.

LOPES, C. L.; LOPES, K. C. S. A. Agricultura urbana ecológica: a experiência de Cuba. Agriculturas, Rio de Janeiro, v. 9, n. 2, p. 39-41, 2012.

LOVELL, S. T. Multifunctional urban agriculture for sustainable land useplanning in the United States. Sustain 2, [s. l.], p. 2499-2522, 2010.

MARQUES, F. C.; CONTERATO, M. A.; SCHNEIDER, S. Construção de mercados e agricultura familiar. Desafios para o desenvolvimento rural. Porto Alegre: Editora da UFRGS, 2016.

MCCLINTOCK, N. Why farm the city? Theorizing urban agriculture through a lens of metabolic rift. Cambridge Journal of Regions. Economy and Society, [s. l.], v. 3, p. 191-207, 2010.

MCMICHAEL, P. Regimes alimentares e questões agrárias. São Paulo: Unesp, 2016.

MEIRELLES, L. Soberania alimentar, agroecologia e mercados globais.

Agriculturas, Rio de Janeiro, v. 1, p. 11-14, set. 2004. 
MELLO, C. S. Leituras e discursos sobre Agricultura Urbana: um debate em construção. In: ENCONTRO NACIONAL DA ASSOCIAÇÃO NACIONAL DE PÓS-GRADUAÇÃO E PESQUISA EM PLANEJAMENTO URBANO E REGIONAL, 18., 2019, Natal. Anais [...] Natal: UFRN, 2019. p. 1-14. MOUGEOT, L. Urban agriculture: definition, presence, potentials and risks, and policy challenges. Cities Feeding People Series. Ottawa, Canada: International Development Research Centre (IDRC), 2000.

NIEDERLE, P. A.; WESZ JUNIOR, V. J. As novas ordens alimentares. Porto Alegre: Editora da UFRGS, 2018.

ORTEGA, J.; SANTOS, A. S.; SOUZA, I. M. D.; OLIVEIRA, A. P. R.; MARJOT'TA-MAISTRO, M. C. Panorama das comunidades que sustentam a agricultura (CSA): os movimentos no Brasil e Europa. Cadernos de Agroecologia, [s. l.], v. 13, n. 1, p. 1-7, jul. 2018.

PALMA, I. P. et. al. Historical changes in the process of agricultural development in Cuba. Journal of Cleaner Production, [s. l.], v. 96, p. 77-84, 2015.

PFEIFFER, A.; SILVA, S.; COLQUHOUN, J. Innovation in urban agricultural practices: responding to diverse production environments. Renewable Agriculture and Food Systems, [s. l.], v. 30, p. 79-91, 2014.

PLOEG, J. D. Camponeses e impérios alimentares: lutas por autonomia e sustentabilidade na era da globalização. Tradução Rita Pereira. Porto Alegre: Editora da UFRGS, 2008.

POLANYI, K. A grande transformação: as origens de nossa época. 2. ed. Rio de Janeiro: Campus, 2000.

PÖLLING, B.; MERGENTHALER, M.; LORLEBERG, W. Professional urban agriculture and its characteristic business models in Metropolis Ruhr, Germany. Land Use Policy, [s. l.], v. 58, p. 366-379, 2016.

PREISS, P. V.; MARQUES, F. C. Tendências no movimento de re-localização alimentar brasileiro: uma análise de Iniciativas Colaborativas de Compras.

Tessituras, Pelotas, v. 3, n. 2, p. 269-300, jul./dez. 2015.

RIBEIRO, S. M.; BOGUS, C. M.; WATANABE, H. A. W. Agricultura urbana agroecológica na perspectiva da promoção da saúde. Saúde Soc., São Paulo, v. 24, n. 2, p. 730-743, 2015.

RUAF. Revista de Agricultura Urbana. [S. l.]: RUAF Foundation, n. 33, 2017. 
SALDIVAR-TANAKA, L.; KRASNY, M. E. Culturing community development, neighborhood open space, and civic agriculture: the case of Latino community gardens in New York City. Agric Hum Values, [s. l.], v. 21, p. 399-412, 2004. Disponível em: https://doi-org.ez3.periodicos.capes.gov. br/10.1007/s10460-003-1248-9. Acesso em: 2 mar. 2021.

SANTANDREU, A.; CASTRO, C. Strengthening Urban Producers

Organisations. RUAF, Urban Agriculture Magazine, [s. l.], v. 1, n. 17, p. 5-7, 2007.

SANTANDREU, A.; LOVO, I. C. Panorama da agricultura urbana e periurbana no Brasil e diretrizes políticas para sua promoção. Belo Horizonte: FAO: MDS: SESAN: DPSD, 2007.

SCHNEIDER, S.; CASSOL, A.; LEONARDI, A.; MARINHO, M. M. Os efeitos da pandemia da Covid-19 sobre o agronegócio e a alimentação. Estudos Avançados, São Paulo, v. 34, n. 100, p. 167-188, 2020. Disponível em: https:// doi.org/10.1590/s0103-4014.2020.34100.011. Acesso em: 2 mar. 2021.

\section{SILVA, H. Socialização da natureza e desenvolvimento na Amazônia}

brasileira. 2017. 267 f. Tese (Doutorado em Economia) - Centro de Desenvolvimento e Planejamento Regional, Universidade Federal de Minas Gerais, Belo Horizonte, 2017.

TEITEL-PAYNE, R.; KUHNS, J.; NASR, J. Indicators for Urban

Agriculture in Toronto: a scoping analysis. Toronto, Canadá: Toronto Urban Growers, 2016.

TEIXEIRA, F. C. Crise alimentar, energia e clima: nova geopolítica da fome?

Ecodebate, Rio de Janeiro, 2007. Disponível em: https://www.ecodebate.com. $\mathrm{br} / 2007 / 11 / 14 /$ crise-alimentar-energia-e-clima-nova-geopolitica-da-fome-porfrancisco-carlos-teixeira/. Acesso em: 2 mar. 2021.

THEBO, A. L.; DRECHSEL, P.; LAMBIN, E. Global assessment of urban and peri-urban agriculture: irrigated and rainfed croplands. Environ. Res. Lett., [s. l.], p. 1-9, 2014.

TORNAGHI, C. Urban Agriculture in the food-disabling city: (re)defining urban food justice, reimagining a politics of empowerment. Antipode, [s. l.], v. 3, p. 781-801, 2017.

TORNAGHI, C.; HOEKSTRA, F. Urban Agroecology. Urban Agriculture Magazine, [s. l.], n. 33, p. 3-4, 2017. 
TORONTO. GrowTO: an urban agriculture action plan for Toronto. Toronto: TFPC, 2012. Disponível em: http://www.toronto.ca/legdocs/mmis/2012/pe/ bgrd/backgroundfile-51558.pdf. Acesso em: 2 mar. 2021.

TORRES, C. L. Comunidade que sustenta a agricultura: a reaplicação da tecnologia social a partir dos casos pioneiros em Brasília. 2018. 108 f. Dissertação (Mestrado em Design) - Instituto de Artes, Universidade de Brasília, Brasília, 2018.

WILSON, G. A. From 'weak' to 'strong' multifunctionality: conceptualising farm-level multifunctional transitional pathways. J. Rural Stud., [s. l.], v. 24, p. 367-383, 2008.

YEUNG, Y. Examples of urban agriculture in Asia. The United Nations University. Food and Nutrition Bulletin, [s. l.], v. 9, n. 2, 1987. 
